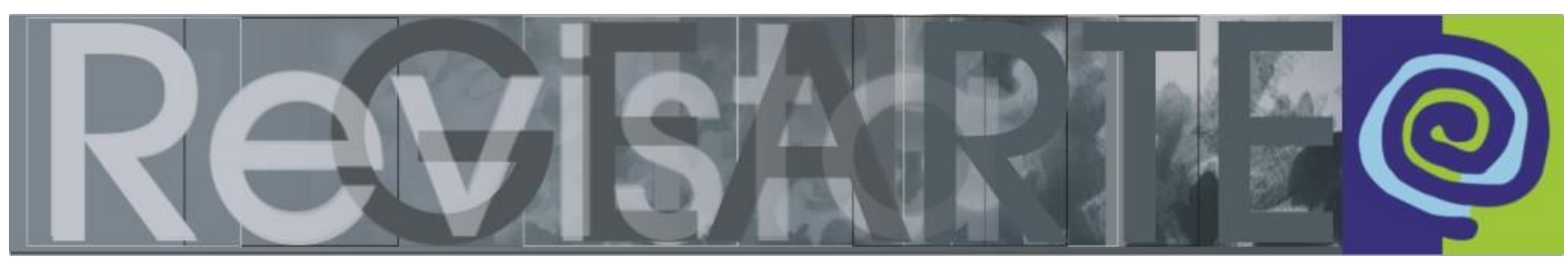

e-ISSN 2357-9854

\title{
Juntos ou Separados: a busca pelo associativismo e o caso APAEP e APROAP
}

\author{
Luzia Aparecida Ferreira-Lia (Universidade Federal \\ do Paraná - UFPR, Curitiba/PR, Brasil) \\ Luciano Parreira Buchmann (Universidade Estadual \\ do Paraná — UNESPAR, Curitiba/PR, Brasil)
}

\begin{abstract}
RESUMO - Juntos ou Separados: a busca pelo associativismo e o caso APAEP e APROAP Neste artigo efetua-se uma análise sobre o associativismo, mais especificamente o caso das entidades de classe Associação dos Profissionais em Arte-educação do Paraná (APAEP) e a Associação dos Professores de Arte do Paraná (APROAP). Para isso, descreve o panorama da política social voltada a educação enquanto política pública, utilizando como suportes a Constituição Federal Brasileira, a Lei de Diretrizes e Bases da Educação (LDB), o Plano Nacional de Educação (PNC), a criação polêmica da Base Nacional Curricular Comum (BNCC) e a Medida Provisória (MP/746), com a intenção de verificar se o associativismo subsidiou as questões/ações relativas ao ensino das artes e quais foram os enfrentamentos que impediram o aceite das sugestões advindas do coletivo das entidades. As bases teóricas estão ancoradas principalmente em BASTOS, FERRETI e SILVA, BARBOSA, FERREIRA, MOTTA e FRIGOTTO, ARELARO, GAMA e nas vivências dos autores, pois ambos são mediadores na área das artes.
\end{abstract}

PALAVRAS-CHAVE

Associativismo. Políticas Públicas Educacionais. Políticas Sociais. Ensino de Artes. Educação.

RESUMEN - Juntos o Separados: la búsqueda por el asociativismo y el caso APAEP y APROAP_ En este artículo presentamos un análisis sobre el asociativismo, específicamente el caso de las entidades de clase la Asociación de los Profesionales en Arte-educación de Paraná (APAEP) y la Asociación de los Profesores de Arte de Paraná (APROAP). Para esto, fue descrito un panorama de la política social orientado a la educación, desde la perspectiva de la política pública, utilizando como subsidios la Constitución Federal Brasileña, la Ley de Directrices y Bases de la Educación (LDB), el Plan Nacional de Educación (PNC), la creación polémica de la Base Nacional Curricular Común (BNCC) y la Medida Provisional (MP / 746). El objetivo fue de verificar si el Associativismo, subsidió las cuestiones/acciones relativas a la Educación Artística y cuáles fueron los conflictos que impidieron aceptar las sugerencias provenientes del colectivo de las entidades. Las bases teóricas están apoyadas principalmente en BASTOS, FERRETI y SILVA, BARBOSA, FERREIRA, MOTTA y FRIGOTTO, ARELARO, GAMA y en las experiências profesionales de los autores, siendo ambos mediadores en el área de las artes.

PALABRAS CLAVES

Asociativismo. Políticas Públicas Educacionales. Políticas Sociales. Educación Artística. Educación.

Falar de Política Pública no Brasil é rememorar episódios de nossa história, principalmente os ocorridos nos meados do século XIX e durante todo o século XX. Nesse período, surgem com mais força as questões relativas às Políticas Sociais, cuja origem remonta ao marco histórico da Constituição do Estado Social. O processo histórico pondo em prática uma política pública para a educação vem desde os FERREIRA-LIA, Luzia Aparecida; BUCHMANN, Luciano Parreira. 259 Juntos ou Separados: a busca pelo associativismo e o caso APAEP e APROAP. Revista GEARTE, Porto Alegre, v. 5, n. 2, p. 259-271, maio/ago. 2018.

http://dx.doi.org/10.22456/2357-9854.83950 
primórdios da República, quando a Constituição já defendia o ensino primário laico e gratuito. Nesse contexto foi criada a,

Associação Nacional da Educação - ANE, que favoreceu o ensino fundamental público obrigatório. Nesse mesmo período aconteceram várias reformas que proporcionavam o estabelecimento, a estrutura e o funcionamento do ensino médio. (BASTOS, 2017, s/p).

As políticas sociais na década de 40 são marcadas pela criação do Serviço de Assistência ao Menor; a Legião Brasileira de Assistência Social, a LBA, significando um grande avanço; a Consolidação das Leis Trabalhistas, CLT, durante o getulismo (1930-1945 e 1951-1955) e o voto feminino. Ao analisar essas conquistas por outro prisma, resta ainda uma dúvida: se vivíamos uma ditadura populista, esses foram direitos ou concessões paternalistas?

Ora, se as Políticas Públicas visam contemplar as necessidades da sociedade civil, enquanto Políticas Sociais, e são determinantes do "padrão de proteção social implementado pelo Estado, voltadas em princípio, à redistribuição dos benefícios sociais" (INEP, 2006, p.165), dentre estes o direito à educação, a implementação de uma política educacional deveria, então, possibilitar a garantia deste com qualidade e de forma universal.

Em 1964 foi sancionada a Lei de Diretrizes e Bases da Educação (LDB/4024) e se estabeleceu a Política Nacional de Bem-Estar Social, processo interrompido com a instauração do regime ditatorial em março daquele ano, havendo perdas consideráveis nessas questões com a criação dos órgãos que cercearam as liberdades de reivindicações, levando o país a um declínio econômico, social e político.

Com o final da ditadura (1985), houve uma explosão de reivindicações sociais exigindo a elaboração de uma nova Constituição (1988). Seu texto trouxe avanços na construção do estado social ao estabelecer como um de seus objetivos em seu artigo 3..:

Construir uma sociedade livre justa e solidária; garantir o desenvolvimento nacional; erradicar a pobreza e a marginalidade e reduzir as desigualdades sociais e regionais; promover o bem-estar de todos, sem preconceitos de origem, raça, sexo, cor, idade e quaisquer outras formas de discriminação (BRASIL, CONSTITUIÇÃO, 1988). 
Dentre as mudanças está o aumento da vinculação de percentuais mínimos dos orçamentos públicos destinados à educação: 18\% para a União e 25\% para estados e municípios. Isso criou o pacto federativo, fazendo surgir 5,6 mil sistemas educacionais, dificultando a formulação e execução de uma política nacional, estadual ou municipal, principalmente porque os ocupantes dos cargos nos vários níveis de governo pertenciam a partidos políticos distintos, com interesses conflitantes.

Nos anos posteriores à aprovação da constituição, a sociedade brasileira organizada em movimentos sociais pleiteia, junto ao governo, seus direitos sociais. A participação dos vários setores da sociedade civil foi de fundamental importância para a construção do projeto da LDB/96 (PLANO NACIONAL DE EDUCAÇÃO, 1997, p.13).

Como se sabe, as políticas públicas para a educação são efetivadas pela LDB e suas leis complementares. Sua base obedece aos princípios da Constituição e visa definir e regularizar o sistema educacional brasileiro. É importante observar que, embora a educação como direito da população seja citada na constituição de 1934, a primeira LDB vai ser editada apenas em 1961, quando é "sugerida a introdução formal da arte na escola" (BARBOSA, 2009, p.88).

Contudo, é importante ressaltar que não basta a existência das leis, é necessária a vontade política dos governos responsáveis pela condução dos rumos do país para a implementação de políticas públicas para determinada área, ou seja, essencialmente elas devem estar contidas nos planos de governo, cabendo a sociedade civil organizada cobrar sua efetivação.

Após o Golpe na democracia ocorrido em 2016, entre as diversas alterações que retraíram a política pública, negando direitos conquistados ao longo de anos de crescimento, evidencia-se: a Proposta de Emenda Constitucional n. .9 95/2016 efetivada pela (PEC) $n . \stackrel{2}{241 / 55}$, que reduziu e congelou o investimento na saúde e educação por 20 anos; a Medida Provisória (MP n. 746), Base Nacional Curricular Comum (BNCC) e a chamada DI "Contrarreforma" (FERREIRA, 2017) do Ensino Médio. 
Quando a reforma surgiu, sem consulta à sociedade civil, a qualidade do Ensino Médio, seu acesso, taxas de evasão e a "identidade e finalidades" já eram debatidos. Nesse debate, colocavam-se de um lado os grupos que defendiam educação política e socialmente emancipadora e do outro, o dos "liberais-conservadores" interessados "em aplicar os princípios que lembram a Teoria do Capital Humano" (FERRETI; SILVA, 2017). Essa "contrarreforma" (MOTTA; FRIGOTTO, 2017), fere princípios da Constituição e atinge sobretudo os filhos da classe trabalhadora que, na sua absoluta maioria, estão matriculados no ensino público.

O Ensino Médio sofreu reformulações quanto à sua carga horária, financiamento e organização curricular, proposta a partir de cinco itinerários formativos - incluindo a formação técnica e profissional -, rompendo com a concepção de "educação básica" norteadora da LDB 9394/96. Surge então a modalidade "estudo à distância" para integralização dos currículos e a ampliação da jornada escolar. Além disso, a falta de docentes habilitados pode ser suprida com a atribuição de "notório saber" a quem atue no Ensino Técnico e Profissional. O Fundo de Manutenção da Educação Básica (FUNDEB) pode então ser utilizado em parcerias com o setor privado, e o currículo foi "enxugado" com a retirada das disciplinas Arte, Filosofia e Educação Física e Sociologia, sendo revista posteriormente, passando a torná-las optativas (FERREIRA; SILVA, 2017 p.289).

Segundo Arelaro (2017, p.13), essa reforma terá como resultado a precarização da formação dos jovens, pois aquelas disciplinas surgem como 'estudos e práticas' e, assim, podem ser consideradas, no máximo, "temas transversais', ou seja, vai-se trabalhar com eles quando der e convier. A aparente contradição em considerar Arte como 'obrigatória' no Art. $2 .^{\circ}$ e como 'estudos e práticas' no Art. 3.', não é mera coincidência, é proposital". De acordo com Motta e Frigotto (2017) é necessário compreender que, para os reformadores, a tal "modernização do currículo" retira as "disciplinas 'inúteis' ou 'desinteressantes', culpadas pela evasão dos estudantes.

Ainda que haja a previsão da oferta dessas disciplinas, não há garantias, uma vez que, segundo o texto da Reforma, é facultativo, ao estado responsável por gerir o Ensino Médio a sua efetivação. A falta de professor, por exemplo, pode acarretar na 
exclusão dessas disciplinas e eixos. Segundo Ferreti e Silva (2017), a base teórica, política e ideológica da MP $n .^{\circ} 746$, possui relação de identidade e "estreita aproximação entre o propósito educacional que orienta a Base Nacional Comum Curricular (BNCC)".

A ideia de uma BNCC já estava presente na Constituição de 1988. Sua pretensão: unificar o currículo de todo território nacional. Seu estudo teve início ainda no governo de Rousseff, sendo aberta à consulta pública via plataforma do MEC. Atualmente, o texto em sua quarta versão está em apreciação no senado, sendo prevista sua aprovação até agosto de 2018, para então ser regulamentado até o final do ano. A discussão nos estados iniciará em 2019 e a implementação em 2020.

A Base é organizada em competências, que são expectativas e direitos de aprendizagem. A aquisição e desenvolvimento das competências seriam "determinantes de um perfil de alunos" e apontariam a construção coletiva de cidadão e sociedade.

Apesar disso, GAMA, ao comparar as competências na BNCC às da "Nova Agenda de Competências para a Europa"1 surgem diferenças que desfavorecem o estudante brasileiro, pois:

\begin{abstract}
O perfil de aluno esperado pela BNCC apenas aparentemente é o mesmo. A incorporação desigual das expectativas europeias em nossa BNCC, [...] cria um futuro cidadão e trabalhador brasileiro, incapaz, por exemplo, de reconhecer os desafios colocados, sobretudo, pelas Artes e Humanidades, e também pelas diversidades cultural, de gênero e de sexo [...]. As restrições aos conteúdos porventura ideologizados, assim como às questões filosóficas, sociológicas, de gênero e sexo impedem que se abram ao mundo fora dos seus locais de trabalho de forma livre, ativa, criativa, consciente de si e do mundo em que se inserem. (GAMA, 2018, s/p.).
\end{abstract}

Na BNCC, "a Arte deixa de ser Área de Conhecimento Específico e aparece como componente curricular, tornando-se subordinada à Área de Linguagens." (PERES, p.30). Isso significa: pode facilmente tornar-se apenas acessório para o ensino de determinado conteúdo de Língua Portuguesa, "acarretando na negligência

Para acessar a expectativa europeia de futuros cidadãos e trabalhadores, consultar <justificando.cartacapital.com.br/2018/01/16/elite-do-atraso-e-base-nacional-curricular-comum-bncc>. 
de seus conteúdos próprios que ajudam na reflexão e na crítica de objetos artísticoculturais situados em diversos tempos históricos e em diferentes contextos culturais". No texto da BNCC, as Linguagens Artísticas são os subcomponentes do componente Arte. Isso pode dar "margem para interpretações equivocadas e para o retorno da famigerada polivalência, tendo como justificativa a necessidade da valorização do trabalho interdisciplinar" (PERES, s/d, p.31).

Com esse mesmo entendimento, a Federação dos Arte-educadores do Brasil (FAEB), reunida em congresso na cidade de Fortaleza (2016), elaborou ofício sobre o Componente Arte no documento da BNCC, com críticas desconsideradas pelo MEC, gerando descontentamento dos membros da federação atuantes na elaboração da BNCC e posterior pedido de desligamento com "retirada de seus nomes da última versão do documento, por se sentirem usados apenas para legitimar o processo" (PERES, s/d, p.32).

Refletindo sobre a Arte, não constar nos componentes curriculares cobrados nos exames nacionais que mensuram o desempenho estudantil, o autor compreende o risco da marginalização da área de conhecimento em relação às disciplinas exigidas nas avaliações. Isso possivelmente incidirá nas licenciaturas, acarretando em "escassez de concursos específicos de professores das Linguagens Artísticas, e consequentemente, a procura dos cursos dessa natureza na Universidade" (PERES, s/d, p.32-33).

Frente a esses impasses, resta a seguinte questão: o associativismo docente ainda seria uma alternativa capaz de contrapor-se frente a essas perdas da classe dos professores de arte e da sociedade?

\section{O Associativismo de Professores}

O associativismo de professores no Brasil existe desde os tempos das Escolas de Corte, contudo, é surpreendente que algumas das reivindicações dos docentes e críticas que recebem permanecem. Lemos (2011, p.75-76) destaca, entre as reclamações o professorado do século XIX, a questão salarial e as condições de 
trabalho, com frequente solicitação pela construção de espaços apropriados para o ensino.

De acordo com LEMOS (2011, p.79), àqueles profissionais eram acusados de falta de qualificação, sendo esta a razão para sua má-remuneração. Essa ideia também fazia parte de um "discurso de desvalorização do professor pelas autoridades", imprensa e políticos, culpabilizando os professores pelos atrasos da sociedade e os problemas da escola.

Mais tarde, durante toda a República Velha estavam presentes diversas correntes ideológicas e movimentos político-sociais, entre eles o integralismo. Segundo Pôrto Júnior (2003, p.23), cada uma tinha sua concepção de mundo, e a educação como forma de tornar seus projetos realidade. Com o tempo, vieram modificações nas políticas educacionais e com elas, o associativismo passa a ter papel importante na vida dos professores, pois as contribuições do coletivo interferem nas mudanças das políticas.

Cardoso (2011, p.2) entende as associações de professores como mutualistas, ou seja, entidade de interesse mútuo, com funções muito além das financeiras, sendo um "fenômeno que envolve assalariados e cujo componente ideológico aponta exclusivamente para a conformação de solidariedades desse grupo social - podendo ou não se transformar em instância de conflitos com outros grupos".

\section{A APAEP e a APROAP, associativismo de Arte do Paraná}

As alterações na legislação educacional não só enfraquecem o sistema educativo, mas também evidenciam o compromisso do governo brasileiro em cumprir os acordos internacionais, os quais dizem respeito apenas às questões econômicas e demonstram o descompromisso total com as políticas sociais no País. O ensino de arte é exemplo, pois tem percorrido um caminho entrecortado por legislações, como o ocorrido a partir do golpe militar de 1964, quando foi retirado oficialmente do currículo, retornando em 71, durante o tecnicismo (BARBOSA, 2009, p. 88-89). 
Nesse tempo não existiam licenciaturas (SILVA et al., 2013, p.29 apud PEDROSA), e as Escolinhas de Arte do Brasil (EAB) e o Movimento Escolinha de Arte do Brasil (MEA), congregaram docentes em todo o país em seus Cursos Intensivos de Arte na Educação ( $\mathrm{CIAE}$ ), realizados em virtude do convênio celebrado com o Ministério da Educação e Cultura (MEC). A força do MEA e de seus CIAE com a presença de convidados internacionais, segundo Sebastião Pedrosa, também pressionaram as autoridades a introduzir a arte no currículo escolar e fortalecer o movimento das associações de arte educadores no Brasil (SILVA et al., 2014, p. 31).

Diante desse contexto, surge então a disciplina Educação Artística para o 1.0 e 2. graus nas modalidades curta e plena, com formação polivalente nas quatro linguagens artísticas o que, na visão do regime de exceção, teria a pretensão da interdisciplinaridade. Posteriormente, com a LDB de 1996, a arte é considerada uma área do conhecimento, e são criadas nas universidades as licenciaturas nas linguagens específicas, contrárias à formação antiga, o que foi uma conquista da luta associativista no país, com forte atuação da FAEB. Destaca-se, então, a atuação dessa associação na melhoria da definição de políticas sociais educacionais para o ensino da Arte no país. Com isso,

A construção desse árduo e belo caminho firmou-se através de lutas, debates, experimentações artísticas, pesquisas e, principalmente, pelo movimento de arte-educadores, iniciado na década de 1980, marcado por inúmeros encontros nacionais, ampliadores de um debate até então restrito a agências formadoras, conselhos, secretarias de educação (BARBOSA, 2009, p.98-99).

Situação semelhante foi a confraternização do professorado paranaense no Congresso da Internacional Society for Education Trought Art/INSEA/Sobreart no Rio de Janeiro em 1984, e o contato com grupos já organizados como dos educadores paulistas, o que incentivou o desejo de união do grupo, descrita por Laila Tarran, secretária na primeira gestão da Associação dos Profissionais em Arte-educação do Paraná (APAEP). No retorno dessa viagem, os professores iniciam reuniões esporádicas, a escrita de um regimento e a busca por advogado para os registros oficiais. 
Ainda sobre importância dos "encontros nacionais, ampliadores de um debate", Barbosa ressalta que "em meio às discussões emergidas" do Festival Latino Americano de Arte e Cultura/FLAAC/Unb - Brasília (1987), e aos "bastidores políticos onde se moldavam a nova LDB", surgia a criação da FAEB, como "uma maneira de congregar a ânsia associativa que germinava nas várias unidades da federação" (BARBOSA, 2009, p. 91). Caso ocorrido no Paraná onde foi fundada em 29 de junho de 1985 a APAEP.

Seu objetivo era o de "congregar os arte-educadores do Paraná, representando, reivindicando e defendendo seus interesses", bem como "promover atividades culturais e de aperfeiçoamento profissional, incentivar a experimentação e a pesquisa e estabelecer intercâmbio com entidades afins, tanto nacionais quanto internacionais" (ARAÚJO, 2006, p.325).

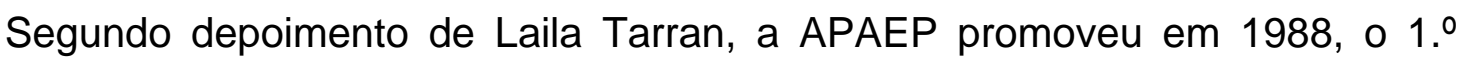
Seminário Sobre o Ensino das Artes Plásticas no Paraná, com aproximadamente cem inscritos, o que serviu para a divulgação e o registro de sócios. Esse seminário ocorreu no Colégio Estadual do Paraná2 , "com debates sobre o ensino das artes plásticas, a formação do arte-educador e do artista plástico". Nesse evento teriam sido traçadas diretrizes de uma política educacional para o ensino das artes (ARAÚJO, 2006, p. 325).

Para a autora, a entidade teria participado do Projeto de Reorganização da Escola Pública de 1.ำ grau, defendendo os direitos dos profissionais da área de artes, e no ano seguinte promovido a exposição "O Desenho Infantil e sua correspondência na Busca do Artista Adulto", com trabalhos infantis. No entanto, Tarran não tem lembrança da participação da APAEP na construção do documento oficial acima citado e ressalta que, devido à dificuldade em marcar reuniões, a pouca assiduidade dos associados e o desinteresse da categoria, a APAEP encerrou suas atividades.

A realização do 1.. Seminário sobre o Ensino das Artes Plásticas no Paraná, ao contrário do que afirma Araújo (2006, p.325) não ocorreu no Solar do Barão e sim, no Colégio Estadual do Paraná. 
Um dos fatores a ser levado em consideração no fechamento das associações regionais, foi a migração dos professores engajados para a universidade e, consequentemente, a transferência da resistência (BARBOSA, 2009, p.91). Após a conquista da Arte na LDB/96, como área de conhecimento, com a abertura das licenciaturas específicas nas diversas linguagens e os concursos de professores o que arrefeceu de certa forma o associativismo.

Depois de quase duas décadas, com o objetivo de discutir o contexto da formação e atuação do professor de arte na região sul, e de também visando a aproximação com a FAEB, a AAESC (Associação de Arte Educadores do Estado de Santa Catarina) e instituições de ensino superior regionais que licenciam professores de arte, a Faculdade de Artes do Paraná (FAP), a Universidade Estadual de Ponta Grossa (UEPG) e a Universidade Federal do Paraná (UFPR), realizaram em 2010, o II Encontro Regional FAEB/Sul, em que se discutiu, novas abordagens para o ensino da arte e os espaços de atuação e de abrangência do campo de ensino de arte na Região Sul.

Desde então alguns professores das licenciaturas e formação continuada, pesquisadores do ensino da arte e professores da educação básica, que consideram o associativismo questão emergente, iniciaram discussões para a reabertura de uma associação de professores de arte no Paraná ${ }^{3}$. As discussões em alguns momentos com maior ou menor força, tendo a redução do grupo inicial, ocorreram no DeArtes (UFPR) e Unespar - FAP. Alguns encontros foram marcados em outras cidades, como o acontecido em Ponta Grossa na UEPG. Outro esforço inicial foi a aproximação ao Polo Arte na Escola da FAP, tentando alcançar o professorado da educação básica.

Entre os fatores que estancaram o movimento inicial do grupo esteve a questão burocrática. A abertura de associações exige estatuto, regimento, contabilidade e custos. A busca dos sócios da APAEP e a antiga documentação da entidade resultou apenas nos depoimentos, mas não teve sucesso no resgate documental. Contudo, 0

3 Ana Nunes - UEPG, Consuelo Schlichta - UFPR; Cíntia Veloso, Luciano Buchmann e Sonia Vasconcellos Unespar - FAP; Roberto Valiente - SEED; Lucineia Droblychlop - SME; Joseane Padilha - SMFRG. 
maior dos desafios perdurou: como mobilizar os professores que, em sua maioria, não possuem a Licenciatura em Arte e desempenham a função, mas não se identificam com a "classe" e seus problemas?

Foi com o advento da BNCC e o retorno de membros do grupo que estavam em qualificação fora do país que se fez a retomada das discussões sobre a abertura da associação. A proposta foi então apresentar o texto inicial da Base aos docentes, debater e participar da construção do documento. As reuniões ocorreram no DeArtes/UFPR, Escolinha de Artes do Colégio Estadual do Paraná e FAP a partir de 2015, divulgados nas redes sociais.

Essas reuniões tiveram a importância de noticiar sobre a movimentação, colher críticas e produzir um arrazoado que subsidiou o texto do grupo sobre a BNCC apresentado no CONFAEB em Fortaleza em 2016. As reuniões tiveram continuidade, algumas com razoável participação, outras esvaziadas, mesmo depois de retirada a disciplina arte do currículo.

O objetivo do grupo em levar a iniciativa da associação no Paraná em frente, fortaleceu-se com o convite ao presidente da AESC em Curitiba que abordou a importância do papel daquela associação participante de conselhos de educação e cultura, com direito a voto. A partir desse encontro, foi escrito um novo regimento e o estatuto do APROAP vem sendo estudado.

Com a intenção de manter certa ligação com o passado da APAEP, o grupo escolheu, a princípio, como nome: Pró- APAEP e posteriormente, APROAP. Atualmente a "Associação" oferta um curso de extensão, em parceria com o Polo Arte na escola e a FAP, cuja intenção é atrair associados.

\section{Considerações Finais}

No Brasil as políticas públicas sociais se caracterizaram por um descompasso entre as proposições do governo e os anseios da sociedade. $\mathrm{Na}$ área educacional esse processo foi marcado pelo associativismo docente com o intuito de reivindicar mudanças nas legislações visando uma melhor qualidade do ensino e de trabalho. 
Foi essa a intenção que moveu professores no passado a fundarem a APAEP, assim como é hoje a da APROAP. Contudo, os esforços para congregar afiliados, tem sido um problema semelhante ao enfrentado pela antiga associação no Paraná. Por incrível que pareça, até mesmo o advento da Reforma do Ensino Médio com a retirada da disciplina Arte do currículo, "rasteira" que atingiu direta e indiretamente o professorado do ensino básico e superior, a mobilização permanece insignificante.

Ao observar essa indiferença, parece que o Ensino da arte navega por mares tranquilos, quando na verdade, os porões do navio têm água e sem a união dos tripulantes, o fim é certo. Se no passado houve a conquista da arte como área de conhecimento, devido à mobilização associativista do professorado, a falta dessa postura dos professores na atualidade pode significar o fim de um projeto de país.

\section{Referências}

ARAÚJJO, Adalice. Dicionário de artes plásticas do Paraná. Curitiba: Edição do Autor, 2006.

ARELARO, Lisete Regina Gomes. Entrevista: Reforma do Ensino Médio: o que querem os golpistas. Revista Retratos da Escola, Brasília, v.11, n.20, p.11-17, jan./jun. 2017. Disponível em: $<$ cnte.org.br/images/stories/retratos_da_escola/retratos_da_escola_20_2017.pdf >. Acesso em: 11 jun. 2018.

BARBOSA, José Mauro Ribeiro. Políticas Públicas para o Ensino de Arte no Brasil. In: RIBEIRO, José Mauro Barbosa. Trajetória e política para o ensino das artes no Brasil: anais do XV Confaeb. Brasília: Ministério da Educação, 2009. p.87-92.

BASTOS, Manoel de Jesus. Políticas públicas na educação brasileira. Revista Científica Multidisciplinar Núcleo do Conhecimento. 5.ed. São Paulo: 2017. Vol.01. p253-263. Disponível em: $<w w w . n u c l e o d o c o n h e c i m e n t o . c o m . b r / e d u c a c a o / p o l i t i c a s-p u b l i c a s>$. Acesso em: 2 jun. 2018.

BRASIL, Lei de Diretrizes e Bases. Lei n.ำ 9.394/96, de 20 de dezembro de 1996. Disponível em:

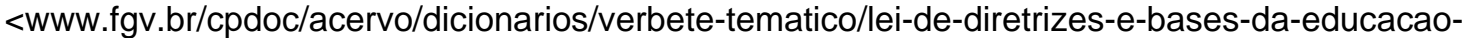
nacional-ldben>. Acesso em: 02 jun. 2018.

BRASIL. Constituição (1988). Constituição da República Federativa do Brasil. Brasília, DF: Senado Federal: Centro Gráfico, 1988.

CARDOSO, Sérgio Ricardo Pereira. Associação Sul-Riograndense de Professores - uma associação mútua docente em Pelotas e região. Santa Maria: 2010. N.1․ 17. Disponível em: <www.eeh2010.anpuhrs.org.br/resources/anais/9/1278281558_ARQUIVO_ASRP_ANPUHRS_ 2010.pdf>. Acesso em: 10 jun. 2018.

FERREIRA, Eliza Bartolozzi. A Contrarreforma do ensino médio no contexto da nova ordem e progresso. Educ. \& Soc., Campinas, v.38, n.139, abr./jun. 2017. Disponível em: <dx.doi.org/10.1590/es0101-73302017176594>. Acesso em: 08 jun. 2018.

FERREIRA, Eliza Bartolozzi; SILVA, Mônica. Centralidade do ensino médio no contexto da nova "Ordem e Progresso". Educ. \& Soc., Campinas v.38, n.139, p.287-292, abr./jun. 2017. Disponível em: <www.scielo.br/pdf/es/v38n139/1678-4626-es-38-139-00287.pdf>. Acesso em: 07 jun. 2018.

FERRETI, Celso João; SILVA, Monica, Ribeiro da. Reforma do ensino médio no contexto da medida provisória n. 746/2016: Estado, currículo e disputas por hegemonia. Educ. \& Soc., Campinas, v.38, 
n.139, p.385-404, abr./jun., 2017. Disponível em: <dx.doi.org/10.1590/es0101-73302017176606>. Acesso em: 07 jun. 2018.

GAMA, Zacarias. Base Nacional Curricular Comum elite do atraso. Ministério da Educação. Carta Capital, Rio de Janeiro, 2018. Disponível em: <justificando.cartacapital.com.br/2018/01/16/elite-doatraso-e-base-nacional-curricular-comum-bncc>. Acesso em: 12 jun. 2018.

INEP/MEC. Enciclopédia de pedagogia universitária: glossário vol. 2. Brasília: Instituto Nacional de Estudos e Pesquisas Educacionais Anísio Teixeira, 2006.

LEMOS, Daniel Cavalcanti de Albuquerque. Professores em movimento: a emergência do associativismo docente na Corte Imperial. Tese (doutorado em educação) - Programa de PósGraduação em Educação - Universidade Federal de Minas Gerais - Faculdade de Educação, Belo Horizonte, 2011. Disponível em: <www.bibliotecadigital.ufmg.br/dspace/bitstream/handle/1843/BUOS8GHNHU/tese_daniel_c._de_a._lemos.pdf?sequence=1 >. Acesso em: 30 maio 2018.

MOTTA, Vânia Cardoso; FRIGOTTO, Gaudêncio. Porque a urgência da reforma do ensino médio? Medida provisória n.․ 746/2016 (LEI n.ำ 13.415/20179). Educ. \& Soc., Campinas, v.38, n.139, abr./jun. 2017.

PERES, José Roberto Pereira. Questões atuais do ensino de arte no Brasil: o lugar da arte na base nacional curricular comum. Revista do Departamento de Artes Visuais, v.1, n.1. Disponível em: <www.cp2.g12.br/ojs/in;ex.php/revistaddav/article/view/1163/859>. Acesso em: 12 jun. 2018.

PÔRTO JÚNIOR, Francisco Gilson Rebouças. Educação na Primeira República (1889-1930) In: APRE NDER - Caderno de Filosofia e Psicologia da Educação, Vitória da Conquista, Ano 1, n.1, p.23-32, 2003. Disponível em: <periodicos.uesb.br/index.php/aprender/article/viewFile/3776/pdf_111>. Acesso em: 8 jun. 2018.

SILVA, Maria Bethânia; SANTOS, Amanda Priscilla; AZEVEDO, Milena Leite de. Memórias não são só memórias: a escolinha de arte do Recife (1953-2013). Recife: Editora Universitária - UFPE, 2013.

\section{Luzia Aparecida Ferreira-Lia}

É Pós-Doutora em Políticas Públicas e Gestão Cultural, Escola Nacional de Antropologia e História do México. Atualmente é pesquisadora e vice-líder do grupo de Pesquisa em Etnomusicologia do Programa de Pós-Graduação em Música da Universidade Federal do Paraná.

E-mail: liafera@usp.br

Currículo: http://lattes.cnpq.br/4366284746568104

\section{Luciano Parreira Buchmann}

É professor na Unespar-FAP, mestre e doutorando em Artes Visuais pela UDESC, sob orientação de Sandra Ramalho e Oliveira na linha de pesquisa Ensino da arte.

E-mail: lucianobuchmann@gmail.com

Currículo: http://lattes.cnpq.br/1073258616943164

Recebido em 31 de maio de 2018 Aceito em 18 de julho de 2018 